\title{
Consumers' Motivations Driving Organic Demand: Between Self- interest and Sustainability
}

\section{Sylvette Monier-Dilhan and Fabian Bergès}

\begin{abstract}
We study consumers' motivations for buying organic food by analyzing their shopping baskets. Buying organic can be motivated by concern about sustainable development and/or self-interest (considerations related to health or product quality). Pro-social motivation is inferred from the presence of fair trade products in the consumer's basket; consumer self-interest is deduced from the presence of healthy and higher-quality products bearing special quality labels or certifications. Our results indicate that environmental motivation predicts organic food purchases better than health or quality considerations: the complementarity between organic and fair trade products is strongest. In addition, the household's socioeconomic background influences secondary motivations.
\end{abstract}

Key Words: basket analysis, econometrics, household demand, organic food

Demand for organic food has grown rapidly in most developed countries in recent years, but 90 percent of the world's organic consumption takes place in North America and Europe. The most distinctive feature of the organic market is a strong growth rate. In France, for example, the market for organic food has doubled since 2007, and in 2012, organic foods represented 4 percent of total food consumption in the United States and 2.3 percent in France (2.5 percent in 2013). Thus, understanding what makes consumers decide to buy organic products despite their higher prices relative to conventional ones is an important economic question. This issue of identifying determinants of consumers' purchases of organic food products

Sylvette Monier-Dilhan is a food economics researcher at the National Institute of Agronomic Research, France. Fabian Bergès is an economist at the National Institute of Agronomic Research - Toulouse School of Economics, France. Correspondence: Sylvette Monier-Dilhan Institut National de la Recherche Agronomique = Observatoire du Développement Rural (ODR) Chemin de Borde Rouge BP 52627 - F-31326 CASTANET TOLOSAN - Cédex (France) - Phone +33 0.561285089 - Email Sylvette.Monier@toulouse.inra.fr.

We thank Marion Desquilbet and Pascal Lavergne for their helpful comments. Funding was provided by the French National Research Agency under the Programme Systèmes Alimentaires Durables 2011 (Sustainable Food Systems Program) OCAD (2011-2014) Offrir et Consommer une Alimentation Durable (Offering and Consuming Sustainable Food) project. The views expressed are the authors' and do not necessarily represent the policies or views of any sponsoring agencies.

Agricultural and Resource Economics Review 45/3 (December 2016) 522-538

(C) The Author(s) 2016. This is an Open Access article, distributed under the terms of the Creative Commons Attribution-NonCommercial-NoDerivatives licence (http://creativecommons.org/licenses/ by-nc-nd/4.0/), which permits non-commercial re-use, distribution, and reproduction in any medium, provided the original work is unaltered and is properly cited. The written permission of Cambridge University Press must be obtained for commercial re-use or in order to create a derivative work. 
has often been addressed with empirical studies for various products in different countries. Using samples of Danish and British consumers' purchases, Wier et al. (2008), for example, concluded that the propensity to purchase organic products tended to increase with social status and the presence of young children in a household. According to Monier-Dilhan et al. (2009), the organic buyer's demographic profile was associated with higher levels of education and was not related to income, age, or family size. The positive influence of education level is consistent with findings by Dettmann and Dimitri (2010) and Dimitri and Dettmann (2012), but those authors also found that income had a positive effect on the likelihood of purchasing and frequency of purchases of organic products. In the latter study, the authors noted several potential reasons for the conflicting results from various studies relating to the product categories and countries concerned and addition of access to organic food as an explanatory variable. Maigné, MonierDilhan, and Poméon (2015) suggested that the spatial structure of the mass distribution network and the local organic supply affected the visibility of organic products in households' environments and thus influenced their buying behavior.

Beyond who buys organic products is the question of why people buy such products. The determinants of organic food choices are complex when analyzed from the consumer's perspective. Conventional agricultural practices (in addition to the food processing industry) are often blamed for damaging the environment through intensive farming (resulting in soil depletion and structural damage) and a heavy reliance on chemical fertilizers (Anderson 2008). Organic practices, in contrast, are part of a general agrofood chain that fosters sustainable development by preserving the environment and biodiversity (Bengtsson, Ahnström, and Weibull 2005). Certainly, the nature of the food supply is shaped by household demand. The growth of the organic market has been attributed in part to consumers' concerns about their health and a resulting desire for organic products that contain no or much smaller amounts of additives, pesticides, hormones, and antibiotics than conventional products. Increasing demand for organic food is also explained by declining consumer confidence in the quality of conventional food and concerns about public health (Saba and Messina 2003, Alvensleben and Altmann 1987, Carboni et al. 2000). Magkos, Arvaniti, and Zampelas (2003) concluded from a review of the literature concerning the nutritional value of food products that nutrition was another driving force.

Hjelmar (2011) distinguished two kinds of organic consumers: (i) "automatic" consumers who buy organic products pragmatically, rely on the official labels, and care about prices and availability, and (ii) "reflective" consumers who tend to buy organic products after thinking about the issue and are committed to promote environmental protection in their daily lives (by, for example, sorting waste and purchasing seasonal foods). Reflective consumers are characterized by social values such as preservation of the common good (Thøgersen 2011), rejection of pesticides (Abrams, Meyers, 
and Irani 2010), trust in organic farming practices (Saba and Messina 2003), and a positive attitude about the environment (Laureati et al. 2013). Unlike pragmatic organic shoppers, reflective shoppers do not regard organic labeling as a sign that such foods are more nutritious or less fattening (WanChen et al. 2013). Furthermore, Wier et al. (2008) showed that many heavy consumers of organic products in terms of buying behavior preferred direct sales because organic labeling often failed to provide detailed information on important attributes such as traceability, production methods, and food miles. According to Aschemann-Witzel, Maroscheck, and Hamm (2013), consumers who frequently purchase organic foods also choose nonorganic foods associated with health claims. In addition, the source of the organic label, whether it is a public label implemented by government authorities or a private one implemented by a nonprofit organization (such as Demeter), may influence consumers' trust in products' characteristics (Janssen and Hamm 2012).

According to several consumer surveys (Magnusson et al. 2003, Mondelaers, Verbeke, and Van Huylenbroeck 2009), health concerns ranked first as the primary motive for purchasing organic foods. Hughner et al. (2007) compiled the findings of 33 studies that investigated people's reasons for purchasing organic food. Despite considerable diversity in consumers' perceptions of organic food, the authors concluded that the primary reason was concern about health and nutrition, followed by taste and concern about the environment. Note, however, that only one of the studies reviewed (Thompson and Kidwell 1998) relied on participants making actual choices; the rest used interviews and/or surveys.

Our goal is to broaden understanding of consumers' reasons for buying organic foods by looking at their actual behavior (Homescan data) rather than relying on declarations of intent. We analyze the composition of consumers' shopping baskets using the market-basket model developed by Russell and Petersen (2000). Monier-Dilhan et al. (2009) used this method with a data set of egg and milk purchases to assess the extent to which an "organic consumer" actually existed (in the sense that a household that purchased organic milk also bought organic eggs) and the impact of prices on the probability of buying organic products. They found that an "organic consumer" did exist. However, that consumer did not have a well-defined socio-demographic profile, and a marginal reduction in the price of the organic products had no impact on the decision to buy organic rather than conventional products.

We address the issue of why the organic consumer buys organic foods. Assuming that the labels on products chosen reflect consumers' motivations, we focus on a set of labels in shoppers' baskets to analyze consumers' motives in terms of the products' healthfulness, environmental impact, and quality (the three main reasons people buy organic food according to the literature) using Russell and Petersen's method as a way to measure and rank complementarities between those motivations. We thus provide new 
insights regarding two important questions: Do consumers buy organic food to promote agricultural sustainability or to meet their desire for healthfulness and/or quality (a private objective) and do socioeconomic characteristics influence the ranking of motives for buying organic food?

\section{Materials and Methods}

\section{Sample}

The analysis relies on 2008 and 2009 Kantar Worldpanel data. ${ }^{1}$ This primary data set records grocery purchases made at mass retail stores for a panel of 22,539 French households and gathers two kinds of information: (i) product characteristics such as prices, categories, brands, label indications, quantities, and promotions for each shopping act using barcodes (universal product codes) and (ii) self-reported socio-demographic characteristics such as family size, income, and education level for each panel household.

We focused on mass-distribution retailers because open-air markets in both traditional and specialized distribution channels are underrepresented in the data. The data set is relevant for studying purchases of organic food products since 47 percent of organic products are sold in hypermarkets and supermarkets (Agence Bio 2013).

Since the aim of the study was to reveal consumers' effective motivations by analyzing the combinations of labels present in their shopping baskets, we selected a basket of common staple goods. To obtain a large number of observations, we chose foods that are usually purchased often and that facilitated our ability to classify consumers' purchasing motivations.

The label categories used in the study are organic, fair trade, healthful, and superior quality. We chose eggs as the representative organic product. Organic eggs are commonly sold in mass retail stores alongside conventional eggs and 68 percent of sales of dairy products and eggs in France come from mass-distribution retailers. ${ }^{2}$ We selected ground coffee for the fair trade (FT) label, margarine enriched with omega 3-6 as the healthful product, and superior-quality cooked ham (French Label Rouge) as the superior-quality (SQ) product. One might suspect that organic consumers would not purchase margarine because of its artificial nature and functional health claims, but the statistics show that 62 percent of the organic consumers in the panel purchased margarine. This is consistent with Aschemann-Witzel, Maroscheck,

\footnotetext{
1 See www.kantarworldpanel.com/global.

2 The most-consumed organic products in France are fruits and vegetables, followed by dairy products and eggs. Fruits and vegetables account for 16 percent of all consumers' expenditures on organic food while eggs and milk each account for 6 percent. Due to limitations of the scanner data, we could not study fruits and vegetables. Purchases of organic fresh fruits and vegetables are not well documented in the data as most do not correspond to universal product codes that indicate clearly whether the purchased product is organic.
} 
and Hamm (2013), which found that even consumers who are intensive buyers of organic goods consume nonorganic goods that offer functional health claims.

Descriptive statistics for the products are shown in Table 1. Market shares are expressed as both revenue value and total quantity for each product. Note that the market share of margarine enhanced with omega 3-6 is significant, unlike the market shares of organic eggs, FT coffee, and, to a lesser extent, SQ ham.

The largest price difference between conventional and organic versions of a product is observed for eggs; the price of organic eggs is 114 percent higher than the price of conventional eggs. Some have claimed (see Hughner et al. 2007) that the weak market share of organic products can be explained by the large price differences. However, Monier-Dilhan et al. (2009) and Bunte et al. (2007) provided evidence to the contrary, showing that a decrease in the price of organic products did not lead to a switch from conventional to organic.

In terms of household characteristics, we focused on family size, income, and education level. Family size is expressed as the number of persons per household. For income, we created a binary variable based on monthly income per consumption unit relative to the median income level. The variable takes a value of 1 when the household's income per consumption unit is above the median and 0 otherwise. The consumption unit accounts for the bigger burden of fixed costs for people who live alone. A household consisting of one adult comprises 1.0 consumption units, each additional adult and child over the age of 15 counts as 0.7 units, and each child age 15 or younger counts as 0.5 units. The variable for education is binary, taking a value of 1 when the head of household has a high school diploma and 0 otherwise. These socio-demographic variables were observed at the time of the purchases (in 2009).

In addition, we calculated an organic-behavior variable that allowed us to characterize the household's propensity to consume organic products using the Kantar data from 2008 for three commonly consumed products: milk, yogurt, and eggs. This variable takes a value of 1 when the share of those three organic products in the household's purchases is greater than the median household share for the products (households that never consumed organic products were excluded from the calculation of the median) and 0 otherwise. Descriptive statistics for these socio-demographic variables are provided in Table 2 . We compared these statistics with national statistics and found that our sample is nationally representative.

\section{The Basket Choice Model}

Russell and Petersen (2000) developed a global utility model that took the fact that the utility derived from consuming a good could be affected by consumption of other goods into account. They analyzed the binary decision to consume or not to consume a product and estimated the determinants of purchase of a combination of goods. The advantage of this basket approach is 
Table 1. Descriptive Statistics of the Market for 2009

\begin{tabular}{|c|c|c|c|c|c|c|}
\hline & \multirow[t]{2}{*}{$\begin{array}{l}\text { Alternatives to } \\
\text { Conventional } \\
\text { Type }\end{array}$} & \multicolumn{2}{|c|}{$\begin{array}{l}\text { Percent Market } \\
\text { Share of the } \\
\text { Alternative }\end{array}$} & \multicolumn{3}{|c|}{$\begin{array}{l}\text { Average Unit Price in Euros } \\
\text { (Standard Deviation) }\end{array}$} \\
\hline & & Value & Volume & Unit & $\begin{array}{l}\text { Conventional } \\
\text { Product }\end{array}$ & $\begin{array}{l}\text { Label } \\
\text { Product }\end{array}$ \\
\hline Eggs & $\begin{array}{l}\text { Organic } \\
\text { agriculture }\end{array}$ & 7.30 & 6.20 & 6 eggs & $\begin{array}{c}1.26 \\
(0.44)\end{array}$ & $\begin{array}{l}2.7 \\
(0.60)\end{array}$ \\
\hline Coffee & Fair trade & 4.40 & 4.18 & 1 kilogram & $\begin{array}{l}10.96 \\
(0.61)\end{array}$ & $\begin{array}{l}13.38 \\
(0.57)\end{array}$ \\
\hline Margarine & $\begin{array}{c}\text { Omega 3-6 } \\
\text { enhanced } \\
\text { (health) }\end{array}$ & 52.85 & 49.91 & 1 kilogram & $\begin{array}{c}3.21 \\
(1.48)\end{array}$ & $\begin{array}{c}5.40 \\
(1.82)\end{array}$ \\
\hline $\begin{array}{c}\text { Cooked } \\
\text { ham }\end{array}$ & $\begin{array}{l}\text { Superior } \\
\text { quality }\end{array}$ & 11.07 & 10.17 & 1 kilogram & $\begin{array}{l}11.00 \\
(0.33)\end{array}$ & $\begin{array}{l}15.09 \\
(0.46)\end{array}$ \\
\hline
\end{tabular}

that the joint probability of purchasing multiple goods can be estimated based on baskets of goods actually chosen by the households under consideration. Furthermore, using Besag's (1974) theorem, Russell and Petersen (2000) showed that the probability of a household choosing a basket of goods could be calculated based on estimation of a standard conditional logistic model in which the choice set was comprised of all possible baskets.

The first step is to specify the model of choice for each good conditional on the effective choice of other goods in each category. We can define the conditional utility of consumer $k$ for consuming product $i$ as

$$
U(i, k)=Z(i, k)+\varepsilon(i, k)=\alpha_{i}+\beta_{i} p_{i k}+\Sigma_{j \neq i} \theta_{i j k} I(j, k)+\varepsilon(i, k)
$$

where $I(j, k)=1$ if the consumer also bought good $j$. The parameter $\alpha_{i}$ is a constant specific for product $i$, and the price paid by consumer $k$ for product $i$ is denoted $p_{i k}$. The final choice of the consumer in favor of good $i$ is also determined by the other goods in her/his basket. The term $\Sigma_{j \neq i} \theta_{i j k} I(j, k)$ allows us to take the choice dependence of good $i$ on decisions concerning the other goods $(i \neq j)$ in the basket into account. The parameter $\theta_{i j k}$ allows us to determine the link between product $i$ and product $j$ for consumer $k$ : $\theta_{i j k}>0$ (respectively $\theta \mathrm{ijk}<0$ ) implies that, for goods $i$ and $j$, household $k$ gains (respectively loses) utility by combining the products. Put differently, the goods can be viewed as complements (respectively substitutes) for each other for consumer $k$. It is assumed that the coefficients are symmetric: $\theta_{i j k}=\theta_{j i k}$. Comparing the magnitude of the cross-effects allows us to rank the complementarity or substitution relationship across labeled products. 
Table 2. Descriptive Statistics of Households' Socio-demographic Characteristics

\begin{tabular}{lcc}
\hline & \multicolumn{2}{c}{ Statistical Source } \\
\cline { 2 - 3 } Socio-demographic Characteristic & Kantar & INSEE \\
\hline Monthly income per unit of consumption in euros & 1.438 & 1.557 \\
& $(765)$ & \\
& median: & \\
Family size (number of persons) & 1.296 & 2.42 \\
& 2.54 & \\
Consumption units & $(1.34)$ & \\
& 1.97 & \\
Percent of participants who had more than a high school & $40.8)$ & \\
diploma & & \\
Percent of participants who bought organic products in 2008 & 12.91 & $(33.5)$ \\
\end{tabular}

Notes: INSEE (Institut National de la Statistique et des Études Économiques) is the French National Statistics and Economic Studies Institute. Standard deviations are given in parentheses.

The conditional probability of buying good $i$ (given the choice of all other products) is the probability that $U(i, k)>0$. If we assume that the error term $\varepsilon(i, k)$ follows a Gumbel distribution, this conditional probability can be written in logistic form:

$$
P(I(i, k)=1 \mid I(j, k) \text { for } j \neq i)=\frac{1}{1+e^{-Z(i, k)}}
$$

where $Z(i, k)$ is the determinist part of the utility expressed in equation 1.

Besag's (1974) theorem allows us to switch from a model of choice for a single product to a model of choice for a set of products. When the distribution for a conditional probability belongs to the exponential family and the coefficients are symmetric $\left(\theta_{i j k}=\theta_{j i k}\right)$, a unique characterization of the joint law exists given the set of conditional distributions. Denoting the realization of basket $B(k)$ by

$$
b=(X(1, b), \cdots, X(i, b), \cdots, X(N, b))
$$

where $X(i, b)=1$ if good $i$ is in basket $b$ and 0 otherwise, and given equations 1 and 2 , the probability of choosing basket $b$ is given by 


$$
P(B(k)=b)=\frac{e^{\mu(b, k)}}{\sum_{b^{*}} e^{\mu\left(b^{*}, k\right)}}
$$

where $b^{*}$ represents the $2^{N}$ possible baskets and $\mu(b, k)$ is the utility of basket $b$ for consumer $k$ :

$$
\mu(b, k)=\Sigma_{i} \alpha_{i} I(i, b)+\Sigma_{i} \beta_{i} P_{i k} X(i, b)+\Sigma_{i<j} \theta_{i j k} X(i, b) \cdot X(j, b) .
$$

This model can predict the probability of choosing each of the $2^{N}$ baskets from the parameters that define the conditional logit models. The model represented by equation 4 then has the form of a standard conditional logit model in which the set of possible choices is the set of baskets and $\mu(b, k)$ is the specification of utility. It can be estimated using the usual process of conditional logit. Each basket can thus be considered as an alternative in the framework of a conditional logit model.

To allow the magnitude of the cross-effects to vary across households, we introduce the socioeconomic variables $\left(D_{k}\right)$ that characterize household $k$. Consequently, $\theta_{i j k}$ is replaced by $\theta_{i j}+\gamma_{i j} D_{k}$ in equations 1 and 4 .

We studied motives for purchasing the organic label using observed purchases of eight foods: eggs, coffee, margarine, and cooked ham in their standard and alternative versions (organic, fair trade, healthful, and superior quality, respectively). To characterize combinations of the labels in purchased baskets to reveal consumers' motivations, we estimated the degree of complementarity between the organic product and the fair trade product to quantify sustainability-driven behavior and the degree of complementarity between the organic product and the (i) superior-quality product (Label Rouge) and the (ii) healthful product to quantify self-interested motives. According to several recent studies, purchases of fair trade goods indicate support for behavior that promotes sustainable development (D'Alessio, De Devitiis, and Maietta 2007, Loureiro and Lotade 2005) because fair trade products improve the living and working conditions of small-scale farmers and agricultural workers in disadvantaged regions. Functional health claims on products, such as "enriched in $\Omega-3$ and $\Omega-6$ " for margarine, an attribute that is thought to reduce cholesterol-related risk, are directed at consumers' self-interested motivations. Label Rouge indicates that a product complies with a specific set of characteristics that result in superior organoleptic quality. By assuming that purchases of products with these labels reflect consumers' buying patterns, we can construct a profile of the organic consumer using the complementarities observed in the basket $\left(\theta_{i j k}>0\right)$.

In terms of possible baskets, the eight goods yield $2^{8}$ distinct baskets. Disregarding the null basket that corresponds to no purchases, we thus had to consider $2^{8}-1$ or 255 baskets. Each household's annual purchases were aggregated to create the shopping basket. 
Since the panel data set covers actual purchases by households, prices for the alternatives they could have chosen were not always known. Prices we did not observe were simulated using a random draw from a log-normal probability distribution with a mean and standard deviation that were based on empirical values for 2009 for purchases observed for the good in question. For the random draws, we took the specific retailer at which the customer had shopped and the region where the customer lived into account. This methodology maintained price heterogeneity among the shoppers.

\section{Results}

The results of the base model are shown in Table 3. The fit of the logistic estimation $\left(\mathrm{R}^{2}=0.29\right)$ allows us to interpret the results with generality. The constants associated with the conventional products are higher than the constants associated with the labeled products in all cases except margarine and reflect the market shares presented in Table 1. The price coefficients are not significant. Of the 28 parameters that measure the complementarity and substitutability between each pair of goods $\left(\theta_{i j}\right), 21$ are significantly positive. Note that similar results are obtained for milk and yogurt as the conventional/organic good (see Appendix 1 for the base model results with milk and Appendix 2 for the base model results with yogurt). ${ }^{3}$ Since the simulation process could cause measurement errors, we checked the robustness of the results by running the model with several alternative price simulations and by estimating an alternative model that omitted the price variables. The results obtained from these alternative estimations were similar to those shown in Table 3.

We find that a marginal change in the price of an organic product has no impact on the probability of buying an organic rather than a conventional product. Since we are looking at an annual basket of staple foods (eggs, margarine, coffee, and ham)-goods that a household is likely to buy on a regular basis and buys at least several times a year if the household purchases them at all-a price change can affect the number of times a product is purchased and/or the quantity bought in that year but is not likely to affect the presence or absence of the product in the annual bundle of goods. This finding is consistent with Bunte et al. (2007), which showed that selling organic products at the conventional price in ten supermarkets in the Netherlands for four months had little impact on demand for organic

\footnotetext{
3 We do not provide a robustness check with substitutes for fair trade, healthy, and superiorquality products (coffee, margarine, and ham respectively) because our data set did not include enough purchases of other food products for observations for both conventional and labeled versions in these categories. Label Rouge chicken would be a good candidate for the superiorquality product but our data did not contain comprehensive information on meat products, and there are no good candidates for the fair trade and healthful products.
} 
Table 3. Estimated Basic Model Parameters

\begin{tabular}{|c|c|c|c|c|c|c|c|c|c|}
\hline & & \multicolumn{2}{|c|}{ Eggs } & \multicolumn{2}{|c|}{ Coffee } & \multicolumn{2}{|c|}{ Margarine } & \multicolumn{2}{|c|}{ Ham } \\
\hline & & $\begin{array}{c}\text { Org. } \\
(j=1)\end{array}$ & $\begin{array}{l}\text { Conv. } \\
(j=2)\end{array}$ & $\begin{array}{c}\text { FT } \\
(j=3)\end{array}$ & $\begin{array}{l}\text { Conv. } \\
(j=4)\end{array}$ & $\begin{array}{c}\Omega 3 \text { and } 6 \\
(j=5)\end{array}$ & $\begin{array}{l}\text { Conv. } \\
(j=6)\end{array}$ & $\begin{array}{c}\text { Sup. Quality } \\
(j=7)\end{array}$ & $\begin{array}{l}\text { Conv. } \\
(j=8)\end{array}$ \\
\hline Constant & & $\begin{array}{c}-1.85^{* *} \\
(0.11)\end{array}$ & $\begin{array}{l}0.30^{* *} \\
(0.08)\end{array}$ & $\begin{array}{c}-3.24^{* *} \\
(0.11)\end{array}$ & $\begin{array}{c}-0.44^{* *} \\
(0.06)\end{array}$ & $\begin{array}{c}-1.80^{* *} \\
(0.06)\end{array}$ & $\begin{array}{c}-1.88^{* *} \\
(0.06)\end{array}$ & $\begin{array}{c}-2.99 * * \\
(0.08)\end{array}$ & $\begin{array}{c}-0.44^{* *} \\
(0.08)\end{array}$ \\
\hline Price & & $\begin{array}{c}0.02 \\
(0.18)\end{array}$ & $\begin{array}{c}-0.03 \\
(0.29)\end{array}$ & $\begin{array}{c}5.70 \\
(4.70)\end{array}$ & $\begin{array}{c}4.50 \\
(2.75)\end{array}$ & $\begin{array}{l}-2.47 \\
(7.20)\end{array}$ & $\begin{array}{r}-12.33 \\
(8.63)\end{array}$ & $\begin{array}{c}2.63 \\
(3.25)\end{array}$ & $\begin{array}{c}9.31 \\
(5.52)\end{array}$ \\
\hline Eggs & $\begin{array}{l}\text { Org. } \\
\theta_{1 j} \\
\text { Conv. } \\
\theta_{2 j}\end{array}$ & & $\begin{array}{c}0.10^{*} \\
(0.06)\end{array}$ & $\begin{array}{c}\mathbf{1 . 1 4}^{* *} \\
(0.05) \\
0.07 \\
(0.07)\end{array}$ & $\begin{array}{c}-0.10^{* *} \\
(0.04) \\
0.67^{* *} \\
(0.04)\end{array}$ & $\begin{array}{c}\mathbf{0 . 3 4} * * \\
(0.04) \\
0.45^{* *} \\
(0.04)\end{array}$ & $\begin{array}{c}-0.37^{* *} \\
(0.04) \\
0.39^{* *} \\
(0.04)\end{array}$ & $\begin{array}{c}\mathbf{0 . 6 1}^{* *} \\
(0.04) \\
0.51^{* *} \\
(0.05)\end{array}$ & $\begin{array}{c}-0.33^{* *} \\
(0.05) \\
1.00^{* *} \\
(0.05)\end{array}$ \\
\hline Coffee & $\begin{array}{l}\text { FT } \\
\theta_{3 j} \\
\text { Conv. } \\
\theta_{4 j}\end{array}$ & & & & $\begin{array}{c}0.77^{* *} \\
(0.07)\end{array}$ & $\begin{array}{c}\mathbf{0 . 1 5}^{* *} \\
(0.04) \\
0.45^{* *} \\
(0.03)\end{array}$ & $\begin{array}{c}-0.07^{* *} \\
(0.04) \\
0.56^{* *} \\
(0.4)\end{array}$ & $\begin{array}{c}\mathbf{0 . 2 3}^{* *} \\
(0.04) \\
0.34^{* *} \\
(0.04)\end{array}$ & $\begin{array}{c}0.00 \\
(0.06) \\
0.72 * * \\
(0.04)\end{array}$ \\
\hline Margarine & $\begin{array}{l}\Omega 3-6 \\
\theta_{5 j} \\
\text { Conv. } \\
\theta_{6 j}\end{array}$ & & & & & & $\begin{array}{l}0.82^{* *} \\
(0.03)\end{array}$ & $\begin{array}{c}\mathbf{0 . 4 1}^{* *} \\
(0.03) \\
-0.00 \\
(0.03)\end{array}$ & $\begin{array}{l}0.20^{* *} \\
(0.04) \\
0.60^{* *} \\
(0.04)\end{array}$ \\
\hline Ham & $\begin{array}{l}\text { Superior Quality } \\
\theta_{7 j} \\
\text { Conv. } \\
\theta_{8 j}\end{array}$ & & & & & & & & $1.30^{* *}$ \\
\hline
\end{tabular}

Note: $\mathrm{R}^{2}=0.29$. Standard deviations are given in parentheses. Error of estimation is noted by ${ }^{* *}$ if less than 5 percent and $*$ if less than 10 percent. 
products. Mondelaers, Verbeke, and Van Huylenbroeck (2009) also found that price was not an important parameter for intensive buyers of organic food. Their basket analysis also examined annual purchases of commonly consumed foods. A quantitative analysis might reveal the classic negative price effect. Monier-Dilhan et al. (2009) concluded that consumers were not price-sensitive when substituting organic products for conventional ones while consumers who had already purchased organic products were pricesensitive.

The sign and magnitude of the $\theta$ values indicate whether and to what extent two products act as either complements or substitutes. A positive (respectively negative) cross-effect indicates that the presence of a product in the annual basket increases (respectively decreases) the likelihood that the other product in the pair will be in the basket. In that case, the goods are viewed as complements (respectively substitutes). Our results suggest that there is complementarity between conventional and labeled versions of ham, margarine, coffee, and yogurt. Organic and conventional milks, on the other hand, act as substitutes and organic and conventional eggs can be viewed as independent products. ${ }^{4}$ A potential explanation for these results is that consumer loyalty to a labeled or conventional product depends on adequate product differentiation. A major characteristic of superior-quality ham is that it tastes better than conventional hams. A consumer's choice of hams could depend on how the product will be used (whether consumed directly or incorporated into a dish). For yogurt, the selection of conventional products offered in stores is typically much greater than the selection of organic yogurts, and consumers may purchase both versions in the course of a year. The selection of conventional coffee (individual/family packaging, instant coffee) is greater than the selection of fair trade coffee so both versions may be present in the annual basket. The complementarity between conventional and omega-enhanced margarine can be explained by use of the omega 3-6 product by household members who have elevated cholesterol levels while others in the household consume conventional margarine. Differentiation of products for conventional milk and eggs is similar to differentiation for organic milk and eggs. We consequently observe consumer attachment to either a labeled or a conventional version.

When we consider pairs of products of the same version (e.g., conventional ham and coffee, organic eggs and margarine, conventional coffee and margarine), we find that the paired products are complements. This result is expected for annual purchases of staple foods. In general, we find that the conventional products have a greater degree of complementarity than the labeled products. The exception is the egg-coffee pair; in that case, the link is

\footnotetext{
4 This result is obtained with a 95 percent confidence interval. For this degree of confidence, the parameter $\theta_{\text {OrgEgg/ConvEggs }}$ is null. With a 90 percent confidence interval, the value of this parameter is small $\left(\theta_{\text {OrgEgg/ConvEggs }}=0.1\right)$.
} 
stronger for the labeled products $(1.14$ versus 0.67$)$. The strong complementarity for the labeled goods may reveal some households' information requirements.

When we consider the cross-effects of an organic food with the other labeled foods, we see that, after controlling for product and price effects, the utility derived by the consumer is greatest when the organic food is combined with fair trade coffee. Complementarity for the coffee combination is 1.14 while complementarity for superior-quality ham is 0.61 and for omega 3-6 margarine is 0.34 . These results are significant at a level of more than 95 percent. The ranking reflects each product's degree of complementarity. Moreover, when we analyze the six cross-effects for the labeled products, we conclude that the organic and fair trade labels have the strongest degree of complementarity. ${ }^{5}$

We can now analyze the results of the market-basket model while allowing the magnitudes of the cross-effects to vary across households. Table 4 presents the impacts of household characteristics on the probability of a purchasing basket $\left(\theta_{i j k}=\theta_{i j}+\gamma_{i j} D_{k}\right)$ containing an organic product. The estimated values of the other parameters (constants and price coefficients) from this model are similar to the ones from the base model. The strongest complementarity is once again between the organic and fair trade labels regardless of the socio-demographic variable considered.

As shown in Table 4, higher-income households clearly exhibit larger crosseffects for labeled products than households with lower incomes. We find that family size has no influence on the link between the organic and fair trade labels or between the organic and superior-quality labels. However, the larger the household is, the less that household combines organic and functional margarine. A greater level of education in the household promotes the perception of organic as environmentally beneficial and strongly diminishes the importance of healthfulness. Finally, intensive consumers of organic food most often combine organic goods with fair trade products (relative to healthful and superior-quality products). ${ }^{6}$

Once again, we find that a change in price does not affect the probability of purchasing a good as the price coefficients are not significant. Second, information about the characteristics of a good clearly matters to consumers who care about production methods and/or social conditions; they tend to combine organic goods with labeled products more often than with conventional alternatives.

The strong complementarity between organic eggs and fair trade coffee relative to complementarities between other pairs of labeled products indicates that organic buyers' net concern is the production method. This

\footnotetext{
5 See the bolded figures in Table 3.

6 The number of households used in this regression is smaller than the number used for the other regressions because these households had to be present in both the 2008 and the 2009 data.
} 
Table 4. Estimates of the Model with Socioeconomic Variables

\begin{tabular}{|c|c|c|c|c|}
\hline & $\begin{array}{l}\text { Income } \\
(k=1)\end{array}$ & $\begin{array}{c}\text { Family Size } \\
\qquad(k=2)\end{array}$ & $\begin{array}{l}\text { Education } \\
\qquad(k=3)\end{array}$ & $\begin{array}{c}\text { Organic Behavior } \\
(k=4)\end{array}$ \\
\hline & \multicolumn{4}{|c|}{ Cross-effects } \\
\hline$\theta_{13}=\theta_{31}$ & $0.85^{* *}$ & $1.18^{* *}$ & $0.85^{* *}$ & $0.44^{* *}$ \\
\hline Org-FT & $(0.07)$ & $(0.09)$ & $(0.07)$ & $(0.08)$ \\
\hline$\theta_{15}=\theta_{51}$ & $0.15^{* *}$ & $0.82^{* *}$ & $0.49^{* *}$ & 0.02 \\
\hline Org-«Health» & $(0.05)$ & $(0.07)$ & $(0.05)$ & $(0.05)$ \\
\hline$\theta_{17}=\theta_{71}$ & $0.35^{* *}$ & $0.52^{* *}$ & $0.37^{* *}$ & $0.19^{* *}$ \\
\hline \multirow[t]{2}{*}{ Org-SQ } & $(0.06)$ & $(0.07)$ & $(0.05)$ & $(0.5)$ \\
\hline & \multicolumn{4}{|c|}{ Socioeconomic $\times$ Cross-effects } \\
\hline Benchmark & $\begin{array}{c}\text { Income }< \\
\text { Median }\end{array}$ & $\begin{array}{c}\text { One } \\
\text { Individual }\end{array}$ & $\begin{array}{c}\text { Education } \\
\text { Level }<\text { High } \\
\text { School Diploma }\end{array}$ & $\begin{array}{c}\text { Organic } \\
\text { Consumption } \\
\text { in } 2008<\text { Median }\end{array}$ \\
\hline$\gamma_{13} \times D_{k}$ & $0.47^{* *}$ & -0.02 & $0.59^{* *}$ & $1.60^{* *}$ \\
\hline Org-FT & $(0.08)$ & $(0.03)$ & $(0.08)$ & $(0.09)$ \\
\hline$\gamma_{15} \times D_{k}$ & $0.34^{* *}$ & $-0.20 * *$ & $-0.34^{* *}$ & $1.04^{* *}$ \\
\hline Org-«Health» & $(0.06)$ & $(0.02)$ & $(0.06)$ & $(0.07)$ \\
\hline$\gamma_{17} \times D_{k}$ & $0.43^{* *}$ & 0.03 & $0.52^{* *}$ & $1.02^{* *}$ \\
\hline Org-SQ & $(0.06)$ & $(0.2)$ & $(0.06)$ & $(0.08)$ \\
\hline $\mathrm{R}^{2}$ & 0.29 & 0.29 & 0.29 & 0.31 \\
\hline Observations & & $\begin{array}{r}5,747,44 \\
(22,539 \times 2\end{array}$ & & $\begin{array}{c}3,891,810 \\
(15,262 \times 255)\end{array}$ \\
\hline
\end{tabular}

Note: Error of estimation is noted as ${ }^{* *}$ if less than 5 percent and ${ }^{*}$ if less than 10 percent.

effect is not linked to the product category because the rankings between the complementarity parameters differ according to whether the product is labeled or conventional. Thus, we can conclude that the strongest complementarity is between the organic and fair trade label. Given that D’Alessio, De Devitiis, and Maietta (2007) and Loureiro and Lotade (2005) showed that fair trade consumers could be characterized by altruistic motives, the strong complementarity identified in this study suggests that organic buyers are primarily motivated by products' production characteristics, which can include social aspects such as farm working conditions and animal welfare (Harper and Makatouni 2002) rather than by healthfulness or quality considerations.

Unlike Hughner et al. (2007), we find that households' socioeconomic characteristics matter, both for predicting organic purchases and for 
understanding consumers' reasons for buying organic. While some socioeconomic variables may alter the secondary motivations consumers have when they buy organic, we find that all types of consumers, regardless of their socio-demographic characteristics, always combine the organic label with the fair trade label. Therefore, consumers' concerns about sustainable production are always ranked as the number-one reason for consuming organic products even though their socioeconomic backgrounds may influence their secondary motivations. The general ranking,

\section{$\theta_{\text {OrgEgg/FTCof }}>\theta_{\text {OrgEgg/QHam }}>\theta_{\text {OrgEgg/HealthMarg }}$,}

is valid regardless of a household's income level. The last inequality is reversed for households with limited education and for one-person households.

Sustainability considerations are reinforced for intensive organic buyers (see last column of Table 4). This may be explained by the fact that such consumers, as profiled by Hjelmar (2011) and Thøgersen (2011), are particularly reflective and conscious of sustainability issues. Accordingly, they would be keener to support fair trade and less favorably disposed toward functional foods. This result demonstrates that consumers who feel strongly about supporting organic products have altruistic motives.

\section{Conclusion}

We examine household purchases of organic food using a basket estimation probability method and rank consumers' three main motives for buying organic products based on actual household buying behavior. Consistent with several prior studies, we find that consumers associate the official label of a product as organic with environmental, health, and quality concerns.

In terms of motivations for buying organic products, we find that consumers who buy an organic product are more likely to also buy a fair trade product than to buy a healthful or superior-quality product regardless of the price effect or category of the goods. Consumers of organic foods thus appear to be motivated more by public attributes such as the social and environmental conditions associated with their production than by personal benefits such as healthfulness and quality. Thus, such consumers value the environmental characteristics more than the possible personal benefits, such as better health due to the absence of pesticides in the products they consume. The originality of this contribution stems from our analysis of actual purchasing behavior. Its main conclusions are valid for the products for which this investigation was possible using our database, that is, eggs, milk, and yogurt for the organic dimension and coffee, margarine, and ham for the fair trade, health, and quality dimensions, respectively. Extending the methodology to investigate other products using other databases would make it possible to assess the robustness of these results. 
In terms of socio-demographic characteristics, we observe that both education and income effects confirm that buyers of organic products are primarily motived by the common good rather than by personal gain. Moreeducated and wealthier heads of households place a relatively greater value on organic labels as guaranteeing sustainable production methods.

A price reduction policy is unlikely to entice new consumers to enter the organic market. Instead, as the results of this study and of Garcia, Fearne, and Wood (2010) indicate, communication strategies aimed at promoting organic agriculture by increasing the demand for organic products should focus on conquering new consumers by emphasizing the environmentally friendly attributes of organic goods. Knowledge of consumers' reasons for purchasing organic products is essential for public authorities, which are always keen to increase organic production to promote long-term sustainable development policy.

Two important issues relating to development of the organic market warrant further research. The first is to consider the impact of mass food retailers' strategy of using their private labels to promote organic consumption, which increases the variety of organic products available to consumers and the range of prices of those products. The second concerns the link between organic production methods and the distance produce travels before commercialization, as traditional retailers may import organic goods to the detriment of their carbon footprint. According to Willer and Kilcher (2012), for example, Europe consumes 47 percent of the world's organic production but devotes only 27 percent of its land to organic production and thus must import organic foods to satisfy demand. Furthermore, our study needs to be complemented by research based on data from multiple distribution channels such as mass retailers, networks specializing in organic sales, and short distribution channels.

\section{References}

Abrams, K., C. Meyers, and T. Irani. 2010. "Naturally Confused: Consumers' Perception of Allnatural and Organic Pork Products." Agricultural and Human Values 27(3): 365-374.

Agence Bio. 2013. "La Bio en France: De la Production à la Consommation (Bio in France: From Production to Consumption)." Available at www.agencebio.org/sites/default/files/ upload/documents/4_Chiffres/BrochureCC/CC2013_chap4_France.pdf.

Alvensleben, R., and M. Altmann. 1987. "Determinants of the Demand for Organic Foods in Germany." Acta Horticulturae 203(28): 235-242.

Anderson, D. 2008. "How Sustainable Is Organic Agriculture?" Presentation to the U.S. Department of Agriculture, Department of Natural Resources and Environmental Sciences, University of Illinois, Urbana.

Aschemann-Witzel, J., N. Maroscheck, and U. Hamm. 2013. "Are Organic Consumers Preferring or Avoiding Foods with Nutrition and Health Claims?" Food Quality and Preference 30(1): 68-76.

Bengtsson, J., J. Ahnström, and A.C. Weibull. 2005. "The Effects of Organic Agriculture on Biodiversity and Abundance: A Meta-analysis." Journal of Applied Ecology 42(2): 261-269. 
Besag, J. 1974. "Spatial Interaction and the Statistical Analysis of Lattice Systems." Journal of the Royal Statistical Society B(36): 192-236.

Bunte, F., M. Van Galen, E. Kuiper, and J. Bakker. 2007. "Limits to Growth in Organic Sales: Price Elasticity of Consumer Demand for Organic Food in Dutch Supermarkets." LEI Report 7.06.20, The Hague. ISBN/EAN: 978-90-8615-127-1.

Carboni, R., M. Vassallo, F. Conforti, and A. D’Amicis. 2000. "Indagine Sulle Attitudini di Consumo, la Disponibilità a Pagare e la Certificazione dei Prodotti Biologicispunti di Tiflessione e Commento dei Risultati Scaturiti [On the Investigation of Consumption Habits, Willingness to Pay, and Certification of Biological Products: Reflection and Comment on a Singular Result]." La Rivista Italiana di Scienza dell'Alimentazione [Italian Journal of Food Science] 29(3): 12-21.

D’Alessio, M., B. De Devitiis, and O. Maietta. 2007. "A Comparative Analysis of the Purchase Motivations of Fair Trade Products: The Impact of Social Capital." Journal for Perspectives of Economic, Political, and Social Integration: Journal for Mental Changes XIII(1/2): 39-87.

Dettmann, R., and C. Dimitri. 2010. “Who's Buying Organic Vegetables? Demographic Characteristics of U.S. Consumers." Journal of Food Products Marketing 16(1): 79-91.

Dimitri, C., and R.L. Dettmann. 2012. "Organic Food Consumers. What Do We Really Know about Them?" British Food Journal 114(8): 1157-1183.

Garcia, C., A. Fearne, and L. Wood. 2010. "The Role of Involvement in the Attention Paid by Supermarket Shoppers to Organic Products." Journal of Innovation Economics 1(5): 127-144.

Harper, G.C., and A. Makatouni. 2002. "Consumer Perception of Organic Food Production and Farm Animal Welfare." British Food Journal 104(3/4/5): 287-299.

Hjelmar, U. 2011. “Consumers' Purchases of Organic Food Products. A Matter of Convenience and Reflexive Practices." Appetite 56(2): 336-344.

Hughner, R., P. McDonagh, A. Prothero, C. Shultz, and J. Stanton. 2007. "Who Are Organic Food Consumers? A Compilation and Review of Why People Purchase Organic Food." Journal of Consumer Behavior 6(2-3): 94-110.

Janssen, M., and U. Hamm. 2012. "Product Labeling in the Market for Organic Food: Consumer Preferences and Willingness-to-pay for Different Organic Certification Logos." Food Quality and Preference 25(1): 9-22.

Laureati, M., D. Jabes, V. Russo, and E. Pagliarini. 2013. "Sustainability and Organic Production: How Information Influences Consumer's Expectation and Preference for Yogurt." Food Quality and Preference 30(1): 1-8.

Loureiro, M.L., and J. Lotade. 2005. "Do Fair Trade and Eco-labels in Coffee Wake Up the Consumer Conscience?” Ecological Economics 53(1): 129-138.

Magkos, F., F. Arvaniti, and A. Zampelas. 2003. "Organic Food: Nutritious Food or Food for Thought? A Review of the Evidence." International Journal of Food Sciences and Nutrition 54(5): 357-371.

Magnusson, M.K., A. Arvola, U-K.K. Hursti, L. Åberg, and P-O. Sjodén. 2003. “Choice of Organic Foods Is Related to Perceived Consequences for Human Health and to Environmentally Friendly Behavior." Appetite 40(2): 109-117.

Maigné, E., S. Monier-Dilhan, and T. Poméon. 2015. "The Impact of the Consumer's Environment on the Demand for Organic Products." Presentation at the 2015 Regional Studies Association Annual Conference, Piacenza, Italy.

Mondelaers, K., W. Verbeke, and G. Van Huylenbroeck. 2009. "Importance of Health and Environment as Quality Traits in the Buying Decision of Organic Products." British Food Journal 111(10): 1120-1139.

Monier-Dilhan, S., D. Hassan, V. Nichèle, and M. Simioni. 2009. “Organic Food Consumption Patterns." Journal of Agricultural and Food Industrial Organization 7(2): 1-23, ISSN (Online) 1542-0485, DOI: 10.2202/1542-0485.1269. 
Russell, G., and G. Petersen. 2000. "Analysis of Cross Category Dependence in Market Basket Selection." Journal of Retailing 76(3): 367-392.

Saba, A., and F. Messina. 2003. "Attitudes towards Organic Food and Risk/Benefit Perception Associated with Pesticides." Food and Quality Preference 14(8): 637-645.

Thøgersen, J. 2011. “Green Shopping: For Selfish Reasons or the Common Good?” American Behavioral Scientist 55(8): 1052-1076.

Thompson, G., and J. Kidwell. 1998. "Explaining the Choice of Organic Produce: Cosmetic Defects, Prices, and Consumer Preferences." American Journal of Agricultural Economics 80(2): 277-287.

Wan-Chen, J., M. Shimizu, K. Kniffin, and B. Wansink. 2013. "You Taste What You See: Do Organic Labels Bias Taste Perceptions?" Food Quality and Preference 29(1): 33-39.

Wier, M., K. O’Doherty, L. Andersen, K. Millock, and L. Rosenkvist. 2008. "The Character of Demand in Mature Organic Food Markets: Great Britain and Denmark Compared." Food Policy 33(5): 406-421.

Willer, H., and L. Kilcher, eds. 2012. "The World of Organic Agriculture: Statistics and Emerging Trends 2012." Research Institute of Organic Agriculture (FiBL), Frick, and International Federation of Organic Agriculture Movements (IFOAM), Bonn. 